\title{
Human evolution and transitions in individuality
}

\author{
Evolución humana \\ y transiciones en la individualidad
}

\author{
PAULO C. ABRANTES \\ University of Brasilia (Brazil)
}

\begin{abstract}
This paper investigates whether it is fruitful to describe the role culture began to play at some point in the hominin lineage as pointing to a transition in individuality, by reference to the works of Buss, Maynard-Smith and Szathmáry, Michod and Godfrey-Smith. The chief question addressed is whether a population of groups having different cultural phenotypes is either paradigmatically Darwinian or marginal, by using Godfrey-Smith's representation of such transitions in a multi-dimensional space. Richerson and Boyd's «dual inheritance» theory, and the explanation it provides of the evolution of cooperation in the hominin lineage, is taken into account to shed light on the way Godfrey-Smith deals with cultural evolution, especially concerning the amount of variation in a population of groups with various cultural phenotypes, the role played by multi-level selection in the evolutionary dynamics of such a population and the adequacy of different modalities of group-reproduction.
\end{abstract}

\section{KEYWORDS}

TRANSITIONS IN INDIVIDUALITY, CULTURAL EVOLUTION, DARWINIAN POPULATIONS, EVOLUTION OF COOPERATION, DUAL INHERITANCE THEORY

RESUMEN

Este trabajo indaga acerca de si es fructífero o no describir el papel que la cultura comenzó a jugar en algún punto en el linaje de los homininos como si se tratara de una transición en la 
individualidad, en referencia a las obras de Buss, Maynard-Smith y Szathmáry, y Michod y Godfrey-Smith. La cuestión principal es si una población de grupos con diferentes fenotipos culturales es o bien paradigmáticamente darwiniana o bien marginal, usando para ello la representación de Godfrey-Smith de tales transiciones en un espacio multidimensional. La teoría de la «herencia dual» de Richerson y Boyd, y la explicación que proporciona de la cooperación en el linaje hominino es tenida en cuenta para arrojar luz sobre el modo en que Godfrey-Smith trata la evolución cultural, especialmente en lo concerniente a la cantidad de variación en una población de grupos con diversos fenotipos culturales, el papel jugado por la selección multinivel en el dinámica evolutiva de tal población y la adecuación de diferentes modalidades de reproducción de grupos.

PALABRAS CLAVE

TRANSICIONES EN LA INDIVIDUALIDAD, EVOLUCIÓN CULTURAL, POBLACIONES DARWINIANAS, EVOLUCIÓN DE LA COOPERACIÓN, TEORÍA DE LA HERENCIA DUAL

A BIOLOGICAL TERMINOLOGY HAS OFTEN BEEN EMPLOYED to describe human groups, as in the use of the concept of organism, or that of superorganism, to depict the functional organization of human societies. I want in this paper to appraise another approach: to look at early hominin groups as being the possible outcome of a transition in individuality (TI), by taking other well-known transitions as models. ${ }^{1}$

In his groundbreaking book The evolution of individuality (1987), Buss tackles fundamentally the problem of the evolution of hierarchical organization, especially that one we find in multicellular organisms. In Buss' view, the chief properties of those kinds of individuals are:

(i) Variation is suppressed at the level of the population of cells.

(ii) There is a division of labor between somatic and reproductive cells.

(iii) There is a bottleneck in reproduction.

(iv) Reproductive cells are sequestered very early in the development of the organism, so that they are buffered against the activity that happens in the somatic cells during the life-cycle of the organism.

1 Those borrowings of concepts go, actually, in both directions, since it is maybe even more common to take concepts used to describe humans groups -for instance, that of societyand apply them to describe other animals: such as in animal societies, or in eusocial animals. Metaphors are too often used in a loose and a-critical way, sometimes for promoting ideological purposes. Furthermore, the borders between metaphorical language and literal language are often fuzzy, as shown by the so called dead metaphors. I think the danger involved in the use of metaphors and analogies, such as those suggested by the concept of individual, are worth taken, given their heuristic potential. 
What characterizes his approach is that such properties and hierarchies in general are not «taken for granted as if it were simply a brute fact about the biological world» (Okasha 2006, p. 218). For Buss, TIs are achieved through the synergy between levels of selection and the mediation of conflicts that might threaten the integrity of new individuals.

Despite differences mostly in their methodology, Michod (1999) attempts also to explain how the levels of organization we find in the natural world originated in the first place. He points to the following levels: genes, chromosomes, cells, multicellular organisms, kinship groups, groups and societies. Michod highlights the evolution of mechanisms to foster cooperation in the populations housed under new organizational levels (taken as levels of selection), as well as mechanisms for mediating conflict between levels. He argues that by means of those mechanisms, in a TI (say, to multicellular organisms) fitness is «exported» from the lower to the upper level of selection.

Michod acknowledges that he takes cooperation in social species as a model to understand all TIs $(1999$, p. 8), what brings forth analogical reasoning as a way to provide unified descriptions of, at the first sight, disparate phenomena. ${ }^{2}$

Buss and Michod don't have much to say about human evolution, though. In a very influential book, Maynard Smith and Szathmáry cover a broader territory and emphasize the role played by language in the transition from «primate societies to human societies» $(1997$, p. 6). This fits well within their general framework, which presupposes that one of the features in common between all TIs is the emergence of new ways for information to be transmitted. They highlight also that in TIs «[...] entities that were capable of independent replication before the transition can replicate only as part of a larger whole after it» (Ibid.id.). This relates to the topic of group selection and its role in TIs, I will be discussing later.

Godfrey-Smith's 2009 book is an important contribution to the ongoing investigation on TIs and builds on that previous work. He emphasizes that, under certain conditions, a Darwinian process can affect the very parameters that are implicated in the evolutionary dynamics of a population, bringing about new kinds of individuals: «evolutionary processes are themselves evolutionary products», he says (2009, p. 15). Embracing explicitly a populational approach, Godfrey-Smith represents in a multi-dimensional space the chief features of Darwinian populations concerning their evolvability, telling «paradigmatic» from «marginal» cases. A TI concludes when a new paradigmatic Darwinian

2 Analogical reasoning is all about going back and forth between source and target to come up with a more abstract description, and it is acknowledgedly a source of models and of a new theoretical language (Abrantes 1999, 2004). 
population (DP) emerges, and transitions are depicted as trajectories in this space.

In my view, Godfrey-Smith did not go as far as he could have in applying to the human case this insightful representation, and I will propose its extension in order to accomodate the cultural realm, taking on board some of the theses on human evolution worked out by Richerson and Boyd in dual inheritance theory.

\section{Cultural evolution}

In a clarifying passage of the chapter on «cultural evolution» of his book $(2009,151)$, Godfrey-Smith argues that, in the cultural realm, we should distinguish «biological» and cultural «types of thing», I will be naming $B P$ and $C P$. Furthermore, there are «individualistic» and group-level descriptions of those Darwinian populations, that can be represented in the following table (Abrantes, 2011b):

\begin{tabular}{|c|c|c|}
\hline Type of thing & Individualistic & Group-level \\
\hline $\mathrm{BP}$ (biological) & $\begin{array}{l}\mathrm{BP}_{\mathrm{i}} \text { - agents having } \\
\text { cultural phenotypes }\end{array}$ & $\begin{array}{c}\mathrm{BP}_{\mathrm{g}} \text { - groups having } \\
\text { cultural phenotypes }\end{array}$ \\
\hline $\mathrm{CP}$ (cultural) & $\mathrm{CP}_{\mathrm{i}}$ - cultural variants & $\begin{array}{c}\mathrm{CP}_{\mathrm{g}} \text { - cultural variants' } \\
\text { bundles }\end{array}$ \\
\hline
\end{tabular}

Table 1 - DPs in the cultural realm

At an «individualistic» level, the populations are either constituted by biological individuals with cultural phenotypes $\left(\mathrm{BP}_{\mathrm{i}}\right)$ or by the cultural variants themselves $\left(\mathrm{CP}_{\mathrm{i}}\right)$. At the group-level, either groups with different cultural phenotypes (cultural groups, for short) make up the population $\left(\mathrm{BP}_{\mathrm{g}}\right)$, or it is otherwise constituted by bundles of cultural variants $\left(\mathrm{CP}_{\mathrm{g}}\right)$. Given this categorization, the main question that arises is whether these populations are paradigmatic or just marginal, as far as their evolvability is concerned. 
In the forementioned chapter, Godfrey-Smith focuses on the $\mathrm{CP}_{\mathrm{i}}$ case. ${ }^{3} \mathrm{His}$ chief question is: what are the effects on the Darwinian dynamics of this population whenever agents (within a group) follow a particular behavior-updating rule? He argues that if they follow a «copy the common rule», $\mathrm{CP}_{\mathrm{i}}$ will not evolve in a paradigmatic way. Elsewhere I went into the details of his argument (Abrantes 2011b), but here I will pursue the program I launched there: to change the focal level to $\mathrm{BP}_{\mathrm{g}}$ instead, that is, to a population of groups having cultural phenotypes. Godfrey-Smith hardly addresses this metapopulation in his book and the main reason for that is his belief that human groups fail to meet some basic criteria for individuality, I will make explicit in the following sections.

I should emphasize straight away that I am not here concerned with a methodological project, namely, that of appraising how fruitful might be the application of biological models to explain cultural dynamics. I am pursuing, rather, a program in the philosophy of nature: how do humans, and culture specifically, fit into our picture of other well-known TIs?

From this point of view, I was intrigued by the fact that when GodfreySmith comes to cultural evolution, he draws back from the bold metaphysical orientation of his 2009 book and adopts, rather, a methodological stance.

This move is even more clear in a recent paper, in which he distinguishes different «kinds of cultural evolution: Darwinian imitation, cumulative cultural adaptation and cultural phylogenetic change» (2012, p. 2160). He does not mention his previous classification of populations in the cultural domain and, in particular, he does not address the issue of possible TIs in this domain. He comes close to it, though, when he discusses the application of «phylogenetic methods» to more «[...] cohesive cultures [that] may be less likely to draw on outside influences, and maintain better boundaries» (Ibid., p. 2168). Those cultures are typically associated to cultural groups or societies with a certain kind of organization.

Godfrey-Smith makes clear the requirements for the application of those methods in this context, and exemplifies with a particular phenotypic trait at the group level: «being a complex chiefdom». He goes on arguing that it «[...] is not a trait that can increase or decrease in frequency within a society, as it is an organizational feature of the whole» (Ibid.,p. 2167-8). I think Godfrey-Smith would accept, nonetheless, that this trait might increase or decrease in frequency in the relevant $\mathrm{BP}_{\mathrm{g}}$ population he talked about in his 2009 book.

The organism metaphor even intrudes in Godfrey-Smith's language when he remarks, correctly from my point of view, that we might have to drop the notion of population when dealing with the cultural dynamics that happens

3 Since the $\mathrm{CP}_{\mathrm{i}} / \mathrm{CP}_{\mathrm{g}}$ distinction is not relevant to my aims here, I will lump both under the first heading. 
inside each group. To rephrase this claim by using the terminology he devised previously, it would not be appropriate to refer to $\mathrm{CP}_{\mathrm{i}}$ populations in that case: «[...] The human and artefactual elements of the culture might be so tightly knitted together that change in the society is more akin to change within a single organism than to change in an evolving population» $(2012$, p. 2167).

He doesn't consider, however, the very possibility of an evolution taking place in the population of those «single organisms», given variations in their fitness (measured, for instance, by differential survival rates in this $\mathrm{BP}_{\mathrm{g}}$ population, I dare say).

This is even more remarkable when Godfrey-Smith comes to the «Discussion» in the final part, where he refers to Whiten and Erdal's paper on huntergatherer groups, published in the very same issue of the journal. Those groups are aptly described as «small groups with an egalitarian structure», but instead of looking at them as making up a DP, he focuses instead on the psychological requirements for cultural phylogenetic change to take place. In next passage, Godfrey-Smith keeps addressing behavioral traits of agents (which constitute the lower-level populations) that might favor the use of phylogenetic methods in those contexts (2012, p. 2169).

Therefore, his focus is not on the evolution of human groups (as possible individuals) but on the dynamics of cultural variants. He is looking for «distribution explanations» and not for «origin explanations» (Godfrey-Smith 2009, p. 42), even though the relevant distribution of traits amenable to phylogenetic methods is among groups and not group-members. ${ }^{4}$ Furthermore, if one can talk of reproduction in this case, it refers to the replication of cultural variants and not to the groups themselves.

Still, Whiten and Erdal's paper admits a metaphysical reading, if their terminology is not taken as plainly metaphorical. They mention, effectively, «forms of cooperation, egalitarianism, mindreading, language and cultural transmission» as elements of a «cognitive and behavioural complex [that] allows a human hunter-gatherer band to function as a unique and highly competitive predatory organism» $(2012$, p. 2119).

As a result of this complex, «the band acts as a highly competitive grouplevel predator». In another passage, Whiten and Erdal focus on mindreading, which they claim «[...] provides a central information processing system unattained by other species» (Ibid., p. 2122).

Like these authors, Wilson and Sober argue that «[...] some aspects of human mentality can also be understood as a form of group-level cognition

4 Godfrey-Smith uses, in the 2012 paper, the expression «origin explanation» when he discusses «cumulative cultural adaptation», but this is not the sense of origin in the context of TIs relevant to the present discussion. 
[...]» (1994, p. 593). In their later book, when they discuss the role multi-level selection plays in fashioning «superorganisms», they compare humans with ants and bees (2003, pp. 126-30).

In the following sections, I will show how the way Godfrey-Smith frames a TI in his 2009 book can help to make clear the conditions in which those claims can be read literally.

\section{CoUld EARLY HuMAN CULTURAL GROUPS HAVE BEEN A «TYPE OF THING»?}

In Godfrey-Smith's approach, this amounts to ask whether $\mathrm{BP}_{\mathrm{g}}$, in the case of hominin groups, might have been a paradigmatic DP. Hence, we have to locate this metapopulation in the Darwinian multi-dimensional space. I dealt with the $V$ (abundance of variation) parameter previously (Abrantes 2011b), and came up with suggestions about how to address other dimensions of this space, as far as $\mathrm{BP}_{\mathrm{g}}$ is concerned. Before moving on, I would like to recapitulate briefly the main points I made there.

What is at stake is the evolutionary dynamics of a population of groups having different cultural phenotypes, especially whenever a conformist behavior-updating rule is followed by the members of those groups. Whenever their behavior is so biased, they are «de-Darwinized» as far as the abundance of variation (in their cultural-behavioral phenotype) is concerned: that is, the population of group-members becomes a marginal one regarding this parameter of their evolvability.

Dual inheritance theorists built models in which biases like conformism plausibly evolved given certain environmental conditions, and played a role in supressing variation inside the group. By the same token, a conformist bias increases variation in the higher-level $\mathrm{BP}_{\mathrm{g}}$ population of cultural groups and helps to maintain that variation despite possible inter-group migration (this is, actually, a requirement for increasing the strength of selection at the group level).

Besides conformism, moral aggression as well as an increasing sensitivity to symbolic markers contribute to maintain variation in $\mathrm{BP}_{\mathrm{g}} .{ }^{5}$ On top of those mechanisms, emotions such as guilt and shame (included in what Richerson and Boyd call «tribal instincts») are taken as elements of a social psychology, that evolved for curbing defection and promoting cooperation inside each group what, arguably, increases group fitness in certain conditions. Using Michod's apt depiction, by those means fitness switches from the level of group-members to the group-level.

$5 \quad C f$. Richerson and Boyd 2005, p. 69; Boyd and Richerson 2005, p. 85; Bowles and Gintis 2011, pp. 52, 113. I guess Godfrey-Smith would accept my rephrasing of the following claim: in those cases the group «[...] takes control over the lives and activities of [cultural agents], especially with respect to their reproduction» $(2009$, p. 124). 
However, even if we accept these results concerning the $V$ parameter, they are not enough to show that $\mathrm{BP}_{g}$ becomes, in that transition, a paradigmatic DP by Godfrey-Smith's criteria. We have to further evaluate how this metapopulation fares regarding other parameters of the Darwinian multi-dimensional space, especially those related to inheritance and reproduction. We should also look at the role played by selection at the group level in shaping a (possible) new evolutionary dynamics in that population, in the context of an origin explanation.

\section{THE EVOLUTION OF COOPERATION}

I mentioned at the beginning that Buss and Michod point to cooperation and to mechanisms for mediating conflict between levels of selection as the underlying basis of TIs. The evolution of cooperation is one of the hot topics in present-day investigations about human evolution, and it is beyond the scope of the present paper to offer even a rough presentation of the main programs that are being developped. ${ }^{6}$ In the following, I will take for granted one of those: Richerson and Boyd's.

According to dual inheritance theory, the evolution of cooperation in large human groups presupposes cultural inheritance, which builds up different niches in the metapopulation of groups. Alongside other mechanisms, this generates «multiple stable equilibria» and we can say, therefore, that between-group variation has «culturally evolved» (Richerson and Boyd 2005, p. 196).

The evolution of cooperation presupposes, in this account, multi-level selection:

(i) agents with different psychological profiles reproduce differentially in the particular cultural niche associated with their group (group-members' selection);

(ii) at the metapopulation level, selection works on the existing variation between the groups themselves (group selection), as a result of different culturalevolutionary trajectories taking place inside those groups, and the prevailing environmental conditions.

In this account, to explain how could have evolved a social psychology for sustaining cooperation in large non-kin groups, we need to deal simultaneously with evolutionary processes going on in different kinds of populations at different levels, which are causally related in a complex way.

6 For an overview of the main options, see Bowles and Gintis 2011, p. 53.

7 Richerson and Boyd 2005; Hammerstein 2003, p. 462; cf. Bowles and Gintis 2011, pp. 50,112. A gene-culture coevolutionary account is also compatible with Wilson and Sober's 
One could rephrase the main elements of the explanation of the evolution of human cooperation I sketched above by using Godfrey-Smith's categorization of DPs in the cultural realm, but it would be cumbersome to do so, since the evolutionary dynamics of all four kinds of DPs have to be taken into consideration. ${ }^{8}$

To be fair, this wouldn't be a mere redescription of the very same points made before, since the framework proposed by Godfrey-Smith points to further questions, concerning the evolvavility of those DPs: are they marginal or paradigmatic? And the other way around: the possible paradigmatic character of the BPg population depends, specifically, on the dynamics of the other populations in the cultural realm.

This leads us back to the issue of origin explanations, and multi-level selection comes to the forefront.

\section{Multi-LEVEL SELECTION}

Multi-level selection (MLS) is, effectively, germane to explaining TIs in several accounts, but recent philosophical analysis has shown that people might refer to different mechanisms when they invoke this process. MLS comes, actually, in two flavors (Okasha, 2006, 56):

(i) In MLS1, individuals are the focal units. Whenever the members of a cultural group, for instance, are the units at stake, different psychological profiles might imply differences in fitness depending on with whom each agent interacts in its neighborhood. The kinds of interaction they engage in vary with the structure of the group. Depending on that structure cooperators, for instance, might grow in number in the population, as a result of selection, compared to free-riders.

(ii) In MLS2, the focal units are the groups themselves. In the case I am interested in here, groups with different cultural phenotypes in a particular environment -what includes the groups they interact with-, might vary in their fitness.

MLS1 and MLS2 have often been conflated because selection at the group level is causally effective in both cases, even though not in the same way (Okasha 2006, p. 59).

two «pathways» to the evolution of human psychological adaptations (1994, p. 600).

8 In some passages, Godfrey-Smith (2009,p. 126) points to this complexity in the context of the reproduction of collectives in general, suggesting that an account of their evolutionary dynamics has to take into consideration two kinds of multi-level selection (see next section). 
With this distinction in mind, I will turn to how Richerson and Boyd conceive group selection and its role in human evolution. Afterwards, I will look anew at Godfrey-Smith's stringent conditions on whether we can legitimately talk about reproduction in the case of cultural groups.

According to Richerson and Boyd, for group selection to be a significant force in evolution three conditions have to be fulfilled: 1) (cultural) variation between groups and mechanisms for maintaining this variation; 2) cultural inheritance in each group; 3) intergroup conflict.

Assuming these requirements, to what kind of MLS are they appealing to? This is not a trivial question, given the complexity of the gene-culture coevolutionary processes Richerson and Boyd assume in their account of the evolution of human cooperation. Nonetheless, I would argue that it cannot be of a MLS2 kind, what requires reproduction, inheritance and adaptations at the group-level .?

Effectively, in a clarifying passage, Richerson and Boyd make clear that for group selection to get a grip on human evolution, «[...] there is no need for groups to be sharply bounded, individual-like entities. The only requirement is that there are persistent cultural differences between groups, and these differences might affect the group's competitive ability» (2005, p. 207).

It is amazing, however, that Richerson and Boyd (1999) use once the term superorganism arguing for the crucial role played by tribal instincts in making possible cooperation in complex societies.

They are not inclined to metaphysical speculations, though: Darwinism is for them just a «toolkit». ${ }^{10}$ In any case, Richerson and Boyd do not consider that explanations based exclusively on kin selection and reciprocal altruism can explain human evolution. ${ }^{11}$ Still, I would like to ask whether cultural group selection, as conceived by them, can bolster a TI in the context of human evolution. The question is, actually, more general: can MLS1 buttress such a transition?

Godfrey-Smith presupposes strict criteria concerning reproduction in acceptable origin explanations, on top of those presupposed by Richerson and Boyd:

9 Bowles and Gintis don't presuppose MLS2 either in their models (2011, p. 49).

10 Richerson and Boyd 2005, p.119; Boyd and Richerson 2005, p. 434; cf. Abrantes 2011a. Therefore, they probably wouldn't underwrite the philosophical use I am making here of their ideas, even though, in some passages, they are willing to compare the evolution of cooperation in complex societies (and the underpinning gene-culture coevolutionary processes) to other dramatic transitions that happened in the history of life (Richerson and Boyd 2005., p. 195).

11 Bowles and Gintis make the same point (2011, p. 50). 
Darwinian language is often applied to social groups and communities in such a way that the focus is on persistence of a group as contrasted with extinction, or growth as opposed to shrinkage [...]. In this book I treat Darwinian processes involving growth and persistence without reproduction as marginal cases [...]. So «cultural group selection» of a significant kind requires differential reproduction, not just differential persistence, even though the border between these is vague (Ibid., 151-2; cf. 118-9).

Richerson and Boyd could be a target here, since their theory exemplifies the roles played by growth - measured by how many offspring group-members a particular group produces -and by group persistence (versus extinction) in a context of inter-group conflict.

Godfrey-Smith asserts, in a nutshell, that «Group selection requires a Darwinian population of groups; groups must vary, reproduce, and inherit features from other groups» $\left(2009\right.$, p. 118-9). ${ }^{12}$ As I have pointed out, these are the conditions for MLS2. I mentioned before that Godfrey-Smith is skeptical about the possibility that cultural groups might reproduce; in this case, $\mathrm{BP}_{\mathrm{g}}$ would not be a paradigmatic DP.

If we are not able to come up with modalities of fitness and reproduction adequate to $\mathrm{BP}_{\mathrm{g}}$ (a conceptual problem), it is worthless to look at MLS2 as a mechanism playing a role in the evolution of that metapopulation. In this case, the preconditions for a TI in human evolution are not met. Theses such as those voiced by Wilson, Sober, Whiten and Erdal, quoted above, as well as the uses of the notion of individual and superorganism applied to human groups, will have to be taken as metaphorical, at most.

Godfrey-Smith acknowledges, however, that the borders between differential reproduction and differential persistence are fuzzy. Given the «permissive attitude» $(2009$, p. 91) he embraces in other hard cases, we are authorized to come up with modalities of reproduction appropriate to cultural groups, that might underwrite a conceivable TI in the human lineage, fueled by cultural inheritance ( $c f$. ibid. pp. 84-6; Dennett 2011).

In the case of cultural groups, the literature mentions, effectively, besides growth and persistence, other modalities of group reproduction that might circumvent Godfrey-Smith's appraisal of the Darwinian status of a BP $\mathrm{g}$ population $^{13}$, such as group fission and colonization.

12 In my understanding, Godfrey-Smith requires here group inheritance and not just group-member inheritance, as in Richerson and Boyd's requirements for group-selection. Due to lack of space, I cannot discuss in this paper inheritance at different levels (cf. Okasha on heritability, 2006, pp. 59,185).

13 Grove et al. 2012; Sterelny 2012, pp. 179-80; Bowles and Gintis 2011, p. 
What is at stake, however, is not just whether $\mathrm{BP}_{\mathrm{g}}$ might fulfill the conditions for being a paradigmatic DP, but to provide a plausible origin explanation of the emergence of that population.

\section{A DIACHRONIC APPROACH}

If we take a diachronic approach (Okasha 2006, pp. 219-20), MLS1 and MLS2 can both play roles in different stages of a TI. ${ }^{14}$ MLS2 is usually considered a necessary mechanism in the final stages of the process, in which a new kind of individual emerges -in our hypothetical case, a paradigmatic DP of human groups. But one cannot invoke MLS2 from the beginning since an individual, with its hierarchical organization, has first to be set up through mechanisms acting at the lower levels (Okasha, ibid., p. 229). Afterwards, MLS2 can get a grip on, playing a crucial role in maintaining the integrity of the new individual -e.g. by keeping in place mechanisms for conflict mediation and for avoiding the risks of disruption by free-riders, that are always a threat.

MLS1 is often mentioned as an important mechanism in the initial stages of TIs, starting over the whole process. In the case I am examining here, kin selection and reciprocal altruism play acknowledgedly important roles in the evolution of cooperation, and can actually be seen as MLS1 mechanisms (Wilson and Sober, 2003; Okasha, 2006, pp. 180-5). After the family group is in place as a unit of selection, as well as agents with the psychological capacities for engaging in reciprocity, the first stage in a transition towards a higher-level individual concludes.

Along these lines, the following stages in a transition towards a paradigmatic population of cultural groups are conceivable:

1) Family groups and small non-kin groups.

2) Large cooperative groups. The stability of these larger non-kin groups might presuppose the evolution of a social psychology, as posited by dual inheritance theorists; a new modality of inheritance has also to be in place for culture to accumulate and to generate variation in the $\mathrm{BP}_{\mathrm{g}}$ population.

3) Groups as full-blown individuals. In this stage, mechanisms for suppressing internal variation and for conflict mediation have to be in place and a new modality of group-level reproduction emerges.

In the first two stages, MLS1 mechanisms drive the transition, and in the last stage a MLS2 mechanism stabilizes it. Evolutionary transitions are

50-1; cf. Okasha 2006, pp. 179, 188.

14 This does not exclude that MLS1 and MLS2 might be acting simultaneously from a certain point of a TI, besides other mechanisms. 
typically gradual and we should not expect sharp boundaries separating these stages ${ }^{15}$ and all those mechanisms might play simultaneously causal roles in some stages..$^{16}$

In a similar vein, Simpson (2011) distinguishes three «phases» in evolutionary transitions: the «aggregate phase», the «group phase» and the «individual phase». To each of those corresponds a «dominant fitness component»: differential expansion, differential viability («persistence»), and differential reproduction proper («fecundity»).

Simpson claims that cultural groups don't have fecundity, the same point made by Godfrey-Smith ( $c f$. Okasha 2006, 58). A transition to the individual phase would also be characterized by a «division of labor» among group-members, especially concerning growth and reproduction. Multicellular organisms, as described by Buss particularly, is clearly taken here as a model. Simpson argues that as far as human cultural groups lack this kind of «partitioning», they «don't have the status of full individuals» (2011, p. 222).

There is no place here to speculate on the existence of analogs of this kind of partitioning in cultural groups. Dual inheritance theory offers, however, useful insights on the existence of differences among group-members concerning their role in the replication of cultural variants (that is, in the dynamics of a $\mathrm{CPi}$ population): some individuals are, for instance, taken as models by other individuals that are biased to imitate them preferentially. ${ }^{17}$

\section{Conclusions}

I attempted to show that the transitions in individuality literature, especially Godfrey-Smith's contributions to it, provides a fertile framework to understand claims, we keep finding in recent publications, to the effect that hominin groups might have functioned as individuals (that is, as paradigmatic Darwinian populations) in our evolutionary past.

Even though I dealt mainly with conceptual problems -were philosophers can expect to make a contribution-, the range of empirical problems related to the topics discussed in this paper is huge.

One conceptual problem I dealt with is the requirements for group-selection to play a role in a possible transition in individuality in hominin evolution, associated with culture as a new inheritance system. In this context, I have shown that group reproduction is a requirement hard to be fulfilled. Data about the

15 Cf. McBrearty and A. Brooks 2000.

16 See Okasha 2006, p.177-8; Sober and Wilson 2003, esp. chapters 4 and 5; Bowles and Gintis 2011, p. 114.

17 Cf. Abrantes 2011b, footnote 12. Refer also to the idea of «reproductive leveling» in Bowles and Gintis, 2011, p.112. 
size of hominin groups, the environmental conditions in which they lived and how these conditions varied, the kinds of interaction they engaged with other groups, migration patterns, etc. are directly relevant to tackle this issue, but they are very hard to be obtained..$^{18}$

The archeological records are poor, difficult to interpret or inexistent. Empirical evidence that can be obtained from extant hunter-gatherer groups, are disputable (see Richerson and Boyd, forthcoming). Empirical data clearly underdetermines, furthermore, the various theories on the evolution of human cooperation that are being presently debated, and probably we will have to live for a long time with controversies about many of the issues involved.

Mathematical modeling and simulations are often employed (especially among dual inheritance theorists) to settle some questions, but this methodology has its limitations given the degree of idealization involved (Abrantes 2011a).

The unavoidable speculative character of this endeavour is not necessarily an obstacle but can be part of the answer, in the sense that a theoretical framework can direct our attention to the relevant data and suggest ways of obtaining and interpreting them.

The timing of a possible transition towards a metapopulation of cultural groups in hominin evolution exemplifies this interplay of conceptual and empirical problems. ${ }^{19}$

I highlighted that a dual inheritance account of the evolution of cooperation -which I adopted as a background in the previous discussions-, presupposes, somewhat paradoxically, that most, if not all, hominin evolution has happened in a scenario of conflict between cultural groups (Bowles and Gintis 2011, p. 113). ${ }^{20}$

Sterelny's main objection to that «Bowles's and Gintis's picture» concerns the purported role of group selection in the evolution of human cooperation, what he denies for empirical reasons: he claims that conflict between huntergatherer bands wasn't as common in the Pleistocene as that picture presupposes (Sterelny 2012,pp. 178-80). He still believes, nonetheless, that «group selection has likely played an important role in hominin evolution» (Sterelny 2012, p. 178), even if he is «now less sure that this is so» (Sterelny 2012, xii) -probably having in mind the bolder position he defended earlier (Sterelny 2003).

18 Grove et al. (2012) combine in an interesting way mathematical modeling and data from various extant primates to predict the fission/ fusion patterns of reproduction of huntergatherer groups coping with increasing population and unstable environmental conditions. See also McBrearty and A. Brooks 2000, esp. pp. 532-3.

19 This should not be a surprise for whoever adopts a naturalistic stance in philosophical investigation.

20 Cf. «parochial altruism» (Bowles and Gintis 2011, p. 113). 
He claims, using Godfrey-Smith's explicit populational approach, that hominin groups might have constituted a DP after all, pointing to the requirements for group selection to get a grip on its evolutionary dynamics:

«[...] Selection on bands is potentially powerful if bands differ from one another in ways that are relevant to the fitness of those bands, and if those differences are transmitted to groups that form as bands fissure. Group selection is made more powerful by any process that leads to groups being internally homogeneous, and different from other groups [...]. So perhaps the expansion of various forms of cooperation within local groups led to the formation of a metapopulation of local hominin groups subject to natural selection» (Sterelny 2012, p. 177).

Sterelny argues that cooperation evolved earlier (maybe even before Homo erectus was in the play), by selection acting at the individual-level, «in an environment of relatively peaceful intercommunity relations» and in a scenario of coevolution between «language, normative thought, conventions, and institutions $[\ldots] \gg(I b i d .$, p. 180).

The traits that were selected at the group-level presupposed cooperation but were relevant, actually, for «risk management», given the pressures of a very unstable physical environment that checked population growth during most of the Pleistocene. Fitness differences between groups didn't comprise, in this scenario, traits relevant for engaging in conflict with other groups but, instead, for cooperation (Sterelny 2012, pp. 189-190). ${ }^{21}$

If the points I made before about the role played by group selection in TIs are on the right track, then the evolution of cooperation in the hominin lineage would not be associated with a transition to individual-like cultural groups. In Sterelny's scenario, group-selection might have played a role in the Holocene, though, when conflict and war became common.22

But Holocene societies were internally much more heterogeneous than Pleistocene hunter-gatherer egalitarian groups. ${ }^{23}$ The models from previous

21 To be fair, Bowles and Gintis acknowledge that cooperation between hominin groups might also have happened in many situations (2011, p. 114; see also Richerson and Boyd, forthcoming). The issue is rather the indispensable role played by conflict in their account of the evolution of human cooperation.

22 Sterelny's problem is, rather, how to explain the maintenance of the «prosocial dispositions» required for cooperation, when war and conflict became common in the Holocene, since these new conditions would favor defection (by free-riders), creating the conditions for a «cooperation crisis» (Ibid., pp. 196-7).

23 Cf. Richerson and Boyd's «work-around mechanisms» in complex societies (Richerson and Boyd, 2005, p. 231). In the first versions of this paper, I was willing to see such internal divisions of a group, compatible with tribal instincts, as a modality of reproduction, besides those I mentioned in the former sections. 
TIs (such as the transition to multicellular organisms) fail in this context, and the application of Godfrey-Smith's multi-dimensional representation, as well as his distinction between marginal and paradigmatic populations, become too much strained.

The role played by group-selection in human evolution keeps being controversial and, consequently, the very possibility of a TI, as well as its timing, in this evolution. ${ }^{24}$

\section{REFERENCES}

ABRANTES, P. 1999: «Analogical reasoning and modeling in the sciences», Foundations of Science 4, n. 3, pp. 237-270. , 2004: «Models and the Dynamics of Theories», Philosophos, 9, n. 2, p. 225270.

, 2011a: «Methodological issues in the dual inheritance account of human evolution», en J. Martínez Contreras and A. Ponce de León (eds.) Darwin's Evolving Legacy. México: Siglo XXI - Universidad Veracruzana, pp. 127-143. , 2011b: «Culture and transitions in individuality», en L.H. Dutra and A. Meyer Luz (eds.), Temas de Filosofia do Conhecimento. Florianópolis: NEL/UFSC, p. 395- 408. Coleção Rumos da Epistemologia, v. 11. http://philsci-archive.pitt. edu/9136/

ABRANTES, P. \& F. ALMEIDA, 2011: «Evolução Humana: a teoria da dupla herança», en P. Abrantes (ed.), Filosofia da Biologia. Rio Grande do Sul: ARTMED, p. 261-295.

BOWLES S. \& H. GINTIS, 2003: «Origins of Human Cooperation», en P. Hammerstein (ed.), The genetic and Cultural origins of Cooperation. Cambridge (MA): The MIT Press, pp. 429-443.

,2011: A Cooperative Species: Human Reciprocity and Its Evolution. Princeton: Princeton University Press.

BOYD R. \& P. RICHERSON, 2005: The origin and evolution of cultures. Oxford: Oxford University Press.

BUSS, L. W. 1987: The evolution of individuality. Princeton (NJ): Princeton University Press.

DENNETT, D. 2011: «Homunculi rule: reflections on "Darwinian populations and natural selection" by Peter Godfrey Smith», Biology \& Philosophy, 26, pp. 475488.

24 I am grateful to the Brazilian Research Agency (CNPq) for the support given to this research project. 
Human evolution and transitions in individuality

GODFREY-SMITH, P. 2009: Darwinian populations and natural selection. Oxford: Oxford University Press. ,2012: «Darwinism and cultural change», Phil.Trans. R. Soc. B, 367, pp. $2160-$ 70.

GROVE, M., E. PEARCE \& R. DUNBAR, 2012: «Fission-fusion and the evolution of hominin social systems», Journal of Human Evolution, 62, pp. 191-200.

HAMMERSTEIN, P. (ed.) 2003: Genetic and cultural evolution of cooperation. Cambridge: The MIT Press.

HENRICH J. \& R. BOYD 1998: «The Evolution of Conformist Transmission and the Emergence of Between-Group Differences», Evolution and Human Behavior, 19, pp. 215-241.

McBREARTY, S. \& A. BROOKS, 2000: «The revolution that wasn't: a new interpretation of the origin of modern human behavior», Journal of Human Evolution 39, n. 5, pp. 453-563.

MAYNARD-SMITH, J.\& E. SZATHMÁRY, 1997: The major transitions in evolution. Oxford: Oxford University Press.

MICHOD, R. 1999: Darwinian dynamics: evolutionary transitions in fitness and individuality. Princeton (NJ): Princeton University Press.

OKASHA, S. 2006: Evolution and the levels of selection. Oxford: Clarendon Press.

RICHERSON, P. \& R. BOYD, 1999: «Complex societies: The evolutionary origins of a crude superorganism», Human Nature: an interdisciplinary biosocial perspective, 10, pp. 253-289.

,2005: Not by genes alone: how culture transformed human evolution. Chicago: The University of Chicago Press.

, (Forthcoming) «Rethinking paleoanthropology: A world queerer than we had supposed», en G. Hatfield (ed.), The evolution of mind. Philadelphia: University of Pennsylvania Press.

SIMPSON, C. 2011: «How many levels are there? How insights from evolutionary transitions in individuality help measure the hierarchical complexity of life», en B. Calcott and K. Sterelny (eds.), Major transitions in evolution revisited. Altenberg: Konrad Lorenz Institute, pp. 199-225.

STERELNY, K. 2003: Thought in a hostile world. Malden (MA): Blackwell. 2012: The evolved apprentice. Cambridge (MA): The MIT Press.

WHITEN, A. \& D. ERDAL, 2012: «The human socio-cognitive niche and its evolutionary origins», Phil. Trans. R. Soc. B, 367, pp. 2119-2129.

WILSON, D. \& E. SOBER, 1994: «Re-introducing group selection to the human behavioral sciences», Behavioral and Brain Sciences, 17, pp. 585-654. , 2003: Unto Others. Cambridge (MA): Harvard University Press. 
Paulo C. Abrantes is an Associate Professor in the Department of Philosophy and in the Biological Institute at the University of Brasília, Brazil.

$\mathrm{He}$ is currently working in the philosophy of biology -focusing on cultural evolution and the evolution of cooperation-, and has also published in the philosophy of mind, in general philosophy of science and in the history of science.

Selected recent publications:

ABRANTES, P.; EL-HANI, C. «Gould, Hull and the individuation of scientific theories». Foundations of Science, v. 14, n. 4, p. 295-313, 2009.

ABRANTES, P. «Human Evolution: Compatibilist Approaches». In: Krause, Décio; Videira, Antonio (orgs.), Brazilian Studies in Philosophy and History of Science: an account of recent works. Boston Studies in the Philosophy of Science, Vol. 290, 2011, p. 171-184.

Email:pccabr@gmail.com 